\title{
The Molecular Mechanisms of Offspring Effects from Obese Pregnancy
}

\author{
Daniel Dowling Fionnuala M. McAuliffe \\ UCD Obstetrics \& Gynaecology, School of Medicine and Medical Science, University College \\ Dublin, National Maternity Hospital, Dublin, Ireland
}

\author{
Key Words \\ Maternal obesity $\cdot$ Epigenetics $\cdot$ Reactive oxygen species
}

\begin{abstract}
The incidence of obesity, increased weight gain and the popularity of high-fat / high-sugar diets are seriously impacting upon the global population. Billions of individuals are affected, and although diet and lifestyle are of paramount importance to the development of adult obesity, compelling evidence is emerging which suggests that maternal obesity and related disorders may be passed on to the next generation by non-genetic means. The processes acting within the uteri of obese mothers may permanently predispose offspring to a diverse plethora of diseases ranging from obesity and diabetes to psychiatric disorders. This review aims to summarise some of the molecular mechanisms and active processes currently known about maternal obesity and its effect on foetal and neonatal physiology and metabolism. Complex and multifactorial networks of molecules are intertwined and culminate in a pathologically synergistic manner to cause disruption and disorganisation of foetal physiology. This altered phenotype may potentiate the cycle of intergenerational transmission of obesity and related disorders.

Copyright (c) 2013 S. Karger GmbH, Freiburg
\end{abstract}

\section{Introduction}

Following conception, embryos are exposed to a myriad of heterogeneous and multifactorial conditions which impact upon the complex processes of foetal growth and development. Genetics, maternal factors, uterine environment and maternal and foetal hormonal status are 
all interlinked and are responsible for the progression of embryo to full term foetus [1]. The sequential and continued involvement of these factors must be tightly regulated to ensure optimal intrauterine homeostasis for the delicate architecture of the developing foetus and to promote healthy pregnancy outcome. Any alteration or variation away from optimal growing conditions can have deleterious and long lasting effects [2]. Maternal obesity, significant weight gain or high dietary fat and sugar intake during pregnancy can be characterised by altered glucose metabolism in which various maternal factors are pathologically altered in such a way that may induce changes in foetal growth and developmental trajectories. Human studies have shown that this may predispose offspring to develop obesity, diabetes, cardiovascular abnormalities, adult schizophrenia and asthma [3-9]. Concurrently, studies in animals have found evidence that offspring from obese and high calorific pregnancy may be predisposed to hypertension, renal disorders, non-alcoholic fatty pancreas and liver disease, metabolic disease as well as possible links to psychiatric disorders such as hyperactivity in ADHD [10-15]. In comparison, a study by Smith et al. [9] has shown that offspring born after significant maternal weight loss as a result of biliopancreatic diversion bariatric surgery show improvements in cardiometabolic markers sustained into adolescence, attributable to an improved intrauterine environment. Increasing maternal BMI also increases obstetric complications for the mother and offspring (congenital malformations, macrosomia) [2, 16, 17]. The Barker hypothesis states that environmental influences acting in foetal life are reflected in impaired growth and development which permanently affect structure and metabolism, leading to increased risk of metabolic disease later in life [3]. Indeed during obese pregnancy, the altered nutrient supply present during sensitive periods of gestation may lead to a response by the foetus to 'program' its organs and tissues in a way that results in long-term alterations to their function [18].

Global obesity rates have been increasing logarithmically over recent decades, indeed doubling since 1980, and in 20081.5 billion adults were overweight and 500 million obese. Of concern are the 43 million children under the age of 5 who were overweight in 2010. Furthermore obesity rates are higher in woman then in men, and consequently young woman are increasingly likely to be obese before pregnancy $[5,19]$. If current trends continue unchallenged, projected figures for overweight and obese individuals will be more than 2.16 billion and 1.12 billion respectively by 2030 [20]. The metabolic phenotype associated with obesity involves several of those factors associated with diabetes, namely insulin resistance and glucose intolerance. These factors are crucial to the development of the metabolic syndrome and concurrently increase the risk of developing type 2 diabetes mellitus (T2DM). Other studies have shown evidence that obesity and rapid linear growth in early childhood significantly increases the risk of developing type 1 diabetes [21]. This 'diabesity' phenotype is a chronic self-perpetuating cycle. Emerging evidence, including substantial evidence from experimental animals, suggests that overweight and obese mothers may predispose their offspring to similar fates later in life, while mothers who undergo weight loss before pregnancy produce healthier offspring with significant improvements in many cardiometabolic markers $[9,16,22,23]$.

\section{Mechanisms Involved}

Epidemiological data and experimental studies in animal models have elucidated several mechanisms which may explain, at least in part, the aetiology of the offspring effects arising from maternal obesity. During development of multicellular organisms, cells become differentiated from one another by changing their genetic programme in response to transient stimuli [2]. Long after the stimulus is removed, 'cellular memory' processes allow cells to 
remember their chosen fate over many cell divisions [24]. Consequently, the obese maternal intrauterine environment constitutes an unfavourable combination of pathogenic factors that appear to interfere with developmental processes during critical time windows causing obstetric complications and lifelong epigenetic malprogramming in offspring. Foetal malprogramming of certain hypothalamic feeding circuits, among other pathways, by means of processes that will be discussed hereafter have been shown in various experimental animal models to be capable of causing persistent effects on the metabolic and feeding activity of offspring and can even be transmitted to the next generation [2,13]. This can predispose these offspring to a host of downstream disorders and pathologies previously mentioned. This review will summarise some of these mechanisms in a temporal manner beginning with mechanisms affecting the early embryo and progressing from there. Topics including:

- Maternal and foetal hyperglycaemia is a primary influencing agent on various downstream molecules and processes vital for the development of key organs and systems such as the heart, placenta, and the hypothalamic-neuroendocrine system.

- The arachidonic acid-prostaglandin, nitric oxide, and inflammatory pathways, in addition to foetal hyperinsulinaemia and insulin resistance have been shown to play important roles in embryo development, cardiovascular and placental function.

- Reactive oxygen species and lipotoxicity are also discussed as aggravators of foetal inflammation and negatively affect foetal development.

- And finally, the nature of permanent metabolic alteration and predisposition to later age onset of disease in offspring is discussed.

\section{Hyperglycaemia}

Glucose is the primary fuel source used by embryos, but fluctuations in maternal blood glucose constitute an unfavourable environment for embryonic and foetoplacental development [22, 25]. Maternal glucose levels correlate with foetal size and adiposity [26]. Excessive blood glucose or hyperglycaemia is believed to be the primary teratogen associated with obese pregnancy and responsible for a wide array of developmental abnormalities [16, $17,27]$. Several mechanisms have been proposed to explain how maternal hyperglycaemia and insulin resistance may alter the intrauterine milieu.

\section{Arachidonic Acid-Prostaglandin and Nitric Oxide Pathways}

Synthesis of prostaglandins and related molecules depends on the availability of arachidonic acid and the activity of cyclooxygenases (COX-1, COX-2). Cyclooxygenases convert arachidonate to many different active prostaglandins in response to a variety of stimuli and have a diverse range of actions [28]. Alterations in prostanoid production as a result of insulin resistance and hyperglycaemia in different tissues depend upon several factors. These include, whether good glycaemic control is adhered to or not, regulation of COX-1 and COX-2 gene expression, and levels and responses to ROS and non-esterified fatty acids (NEFAs) [28, 29].

Nitric oxide (NO) is an important player in the arachidonic acid-prostaglandin pathway. NO is constitutively expressed in vascular endothelium by endothelial NO synthase (eNOS) and inducibly expressed in immune cells by inducible NO synthase (iNOS) after stimulation by cytokines, lipopolysaccharides and other immunogenic agents [28]. NO activates haemecontaining enzymes such as COX, which stimulates the production of prostaglandins in different tissues [30]. Thus NO seems to act as a positive regulator of prostaglandin production. 
During normal embryonic development, prostaglandins and NO play crucial roles in various key stages. However too much or too little of either can lead to deleterious effects downstream. Obesity presents increased concentrations of oxidised low-density lipoprotein (oxLDL) [31] and inflammatory molecules such as TNF- $\alpha$ [32], which both cause the downregulation of eNOS expression, via a reduction in its mRNA half-life [29]. Protein kinase $\mathrm{C}_{\beta}$ $\left(\mathrm{PKC}_{\beta}\right)$ has been shown to be activated in insulin-resistant states and capable of inhibiting phosphatidylinositol-3 kinase (PI3k) and eNOS activity and expression [29,33]. As a result, decreased NO production negatively impacts prostaglandin function. Prostaglandins, and in particular $\mathrm{PGE}_{2}$, have shown to be essential in follicular maturation and ovulation. NO is also involved in oocyte maturation, ovulation, fertilization and implantation [34]. During this time period there is an increase in both $\mathrm{PGE}_{2}$ and COX-2 in the ovaries [28]. Studies have shown that impaired meiotic maturation, impaired ovulation, insensitivity to exogenous gonadotropin therapy and depressed ovarian steroidogenesis may occur in association with the hyperglycaemic state $[35,36]$. Indeed maternal hyperglycaemia in mice has shown to adversely affect pre-implantation progression from a one-cell to blastocyst stage. Mouse blastocyst cells were effectively starved as a result of the down-regulation of facilitative glucose transporters. This reduction in available glucose is sufficient to induce apoptosis in the embryo and along with altered $\mathrm{NO}$ and prostaglandin production may account for impaired growth and development [37-40]. Insulin treatment early in gestation normalises glycaemia and concurrently improves embryo development and restores normal cell number in both the inner cell mass and trophectoderm of blastocysts [41].

\section{Reactive Oxygen Species}

NO is no more reactive than oxygen, but its toxicity is vastly enhanced when it reacts with superoxide to form peroxynitrite. NO is the only biological molecule produced at sufficiently high concentrations to out-compete the anti-oxidant superoxide dismutase for superoxide binding [42]. Peroxynitrite inflicts significant cellular damage by inducing lipid peroxidation, oxidisation of sulfhydryl groups in proteins, and nitrate amino acids (e.g. tyrosine) which can affect many signalling transduction pathways [42]. Peroxynitrite also causes DNA strand breakage and mutagenesis, and subsequently results in the activation of nuclear enzyme poly(ADP-ribose)synthetase (PARS), which causes cellular energy depletion (decreased mitochondrial respiration) and cellular injury [43]. Both prostaglandins and NO have been found to play a role in the destruction of $\beta$-cells in pancreatic islets of Langerhans. However NO seems to play a biphasic role in reproduction, in that a narrow range of NO concentrations, usually low, will stimulate and enhance important early events in reproduction, whereas a lack of NO or too much NO has negative consequences [34]. Chronic increases in ROS production in mitochondria in response to hyperglycaemia, plus damage inflicted during embryogenesis can lead to a catastrophic cycle of mitochondrial DNA damage, functional decline, further ROS generation, cellular injury and apoptosis [44, 45]. For example; ROS can directly impair contractile function by modifying proteins central to excitation-contraction coupling, such as the critical thiol groups on ryanodine receptors, thereby enhancing their open probability, suppression of L-type calcium channels and inhibition of $\mathrm{Ca}^{2+}$ uptake in the sarcoplasmic reticulum by means of oxidative interaction with $\mathrm{Ca}^{2+}$ ATPase [46]. ROS can also affect myocardial development and function by means of activating many downstream signalling pathways involved in myocardial growth [44, 45], matrix remodelling, and cellular dysfunction. A broad range of hypertrophic signalling kinases and transcription factors can be stimulated by ROS, including Src (tyrosine kinase), Ras (GTP-binding protein), PKC, mitogen-activated protein kinase, and Jun-nuclear kinase (JNK). Low levels of ROS are asso- 
ciated with protein synthesis, whereas higher levels of ROS induce mitochondrial and DNA damage and apoptosis [44, 47].

ROS can also indirectly impact myocardial development/function. For example, in adult hearts, inflammatory mediators can be stimulated by ROS to subsequently activate myocardial matrix metalloproteinases which promote the progression of cardiac remodelling [44]. Furthermore, Eriksson et al. [48] found that the addition of reactive oxygen scavenging enzyme superoxide dismutase to cultured rat embryos protected against the teratogenic effects of hyperglycaemia. Secondly, the cytoprotective role of NO on cardiac physiology (which includes coronary vasodilation, inhibition of platelet and neutrophil adhesion and activation and modulation of cardiac contractile function) can be reversed when it forms peroxynitrite [49]. ROS have also been shown to stimulate cardiac fibroblast proliferation and cardiomyocyte hypertrophy directly [50]. Once activated, embryonic fibroblasts stimulate embryonic cardiomyocyte proliferation in utero [51]. Cardiac fibroblasts account for up to two thirds of cells in the adult heart [52] and unlike adult cardiomyocytes, adult cardiac fibroblasts can proliferate and increase deposition of extracellular matrix (ECM) proteins such as fibronectin and collagen, which induce interstitial fibrosis and increased passive stiffness of the myocardium that leads to cardiac dysfunction [53]. Angiotensin-II, the main effector peptide of the renin-angiotensin system, can induce cardiomyocyte hypertrophy and cardiac fibroblast proliferation via the $\mathrm{AT}_{1}$ receptor by means of intracellular ROS intermediates. [54]. Accordingly, cardiac fibroblast proliferation and cardiomyocyte hypertrophy, combined with increased synthesis of ECM proteins such as collagen and fibronectin, may lead to ventricular remodelling and cardiovascular disease. Human and animal studies have shown a higher prevalence of cardiovascular disorders in offspring from obese pregnancy compared to normal pregnancy [55-57].

\section{Lipotoxicity and Placental Function}

Studies have shown that obese woman accumulate more upper-body fat, whereas lean woman accumulate fat in the lower-body compartment during pregnancy [58, 59]. This is important as visceral fat is associated with an abnormal metabolic and adipokine profile [60]. Upper-body fat is more prone to lipolysis and produces approximately $60 \%$ of circulating NEFAs compared to only 15-20\% circulating NEFAs produced by lower-body fat stores [60]. Hypertrophic obesity or the enlargement of adipose cells in the upper-body causes an inhibition of fatty acid uptake with increased lipolysis, inflammatory cell infiltration and adipokine secretion [61]. This causes lipotoxicity, which involves the release of excess NEFAs into circulation which accumulate in organs and tissues (heart, liver, muscle) [62]. When intracellular levels of fatty acids become too much for the cell to cope with, cellular disturbances occur, including excessive oxidation of fatty acids causing ROS production, disruption in cell membrane and phospholipid composition as well as changes in ceramide signalling and cholesterol content [63]. This hypertrophic obesity with lipotoxicity, inflammation and cellular dysfunction can cause local insulin resistance with decreased insulin receptor substrate-1 (IRS-1) and GLUT4 protein content [62]. Elevated lipid levels and oxidative stress lead to the production of three harmful oxidised lipid products: lipid peroxides, oxidised lipoproteins and oxysterols [60]. High NEFA levels can produce NO radical formation in smooth muscle and endothelial cells [60], and like ROS, NEFAs can also directly inhibit NO bioavailability [29] and activate NADPH oxidase and the electron transport chain to generate superoxide [64] which damages cell structures such as mitochondria. Oxysterol production during lipotoxic conditions may impact on placental development and function [60]. oxLDLs containing high amounts of oxysterols and phosphatidylcholine hydroperoxide derivatives 
provide ligands for liver X receptor $\alpha$ and $\beta$ (LXR $\alpha$ and $\beta$ ) and peroxisomal proliferator-activated receptor $\gamma$ (PPAR $\gamma$ ) expressed on human placenta, and may alter lipid transport and metabolism. Furthermore the interaction between oxLDL and LXR $\beta$ is involved in the inhibition of human trophoblast invasion in vitro in a concentration-dependent manner [65]. Studies in sheep found maternal obesity increases placental fatty acid transporter expression, foetal blood triglycerides, inflammatory signalling pathways (PPAR $\gamma$ ) and enhances cytokine expression in mid-gestation [66]. Zhu et al. [67] found that maternal and foetal blood concentrations of cholesterol and triglycerides were significantly higher in obese pregnancy. Triglycerides cannot cross the placenta; instead, placental lipases free NEFAs from triglycerides, and these cross over to the foetus where they are transported to the foetal liver via albumin, red blood cells and $\alpha$-fetoprotein, where they are re-assembled into triglycerides. Therefore excess NEFAs and lipotoxicity in the foetus may induce detrimental cascades which impact on many developmental pathways and cellular memory processes.

\section{Hyperinsulinaemia}

Early gestational hyperglycaemic conditions can induce significant deleterious effects on embryonic physiology by causing the death of crucially important progenitor cells and inflicting potentially irreversible damage to others. In mid to late gestation however embryos begin producing their own insulin to regulate glycaemia and growth. Unfortunately this process quickly changes from a helpful mechanism needed for ameliorating high levels of circulating blood glucose to one of a pathogenic accomplice to hyperglycaemia. Insulin decreases blood glucose by triggering liver, muscles and adipose tissue to absorb glucose from circulation and storing it as glycogen or fatty acids [68]. High amounts of insulin are produced in response to overwhelming concentrations of foetal blood glucose. Consequently, high glucose levels combined with high insulin levels cause rapid foetal growth and offspring born large for gestational age or macrosomic. Secondary to macrosomia, foetal hyperinsulinaemia has also been associated with the development of hypertrophic cardiomyopathy $[69,70]$. Cardiomyopathy can be characterised by increased passive tension of embryonic myocytes and delayed relaxation time which impair diastolic function and exacerbate foetal hypoxia. Passive stiffness of the myocardium is determined by collagen-based stiffness of the ECM, and titin-based stiffness of the myofilaments [71]. Isoform switching of the giant elastic protein titin is one of the main mechanisms involved in altering passive myocardial stiffness in perinatal heart development and chronic heart disease. In the mammalian heart, titin exists in two main isoforms, both expressed in sarcomeres - the longer more compliant N2BA isoform and the shorter, stiffer N2B isoform [71]. Krüger et al. [71] described how insulin can regulate titin isoform expression with a preference towards increased N2B expression. Furthermore they elucidated that titin isoform shift towards the stiff N2B was reliant on PI3k/Akt signalling pathway and that activation of PI3k increased phosphorylation of Akt at serine 473 by a factor of 4.6 in response to insulin treatment. The authors also discovered that the PI3k activation of mTOR(mammalian target of rapamycin) was important in N2B expression. Moreover, titin stiffness can be altered without any changes in titin-isoform expression. The activation of the mTOR/rictor complex by insulin enhances (PKC $\alpha$ ) activity. Phosphorylated PKC $\alpha$ and oxidative stress-related disulphide bridge formation in the cardiac specific N2B-titin domain increase myocardial stiffness, whereas protein kinase Gor protein kinase A-mediated titin phosphorylation can soften both cardiac titin isoforms [72-74]. Consequently, the multifactorial nature of the obese intrauterine environment may contribute to altered function in cardiomyopathy. Studies using adult rats found that this was a result of increased myocardial fibrosis and collagen volume fraction, higher intra-myocardial vascular 
advanced glycation end product deposition, and higher cardiomyocyte resting tension which may be related to insulin-induced increase in stiff N2B-titin isoform [71, 75]. Because many of these processes persist throughout the life of obese/overweight individuals, these factors may contribute to heart disease and dysfunction and may account for the increased risk of later life cardiovascular disease in offspring of obese pregnancy [55-57].

\section{Insulin Resistance}

Insulin secretion doubles between the first and third trimester, followed by progressive insulin resistance. This seems to be a natural process that restricts maternal glucose uptake to ensure adequate glucose availability for the growing foetus [23]. However obese mothers have an overproduction of insulin combined with insulin resistance (T2DM), which results in maternal and foetal hyperglycaemia [76]. Diets rich in saturated fatty acids have been shown to play important roles in the onset of obesity-induced insulin resistance. Free fatty acids (FFA) bind to the innate immune receptor TLR4 on adipocytes and macrophages [77]. This leads to production of pro-inflammatory cytokines such as TNF- $\alpha$. Adipose tissue macrophages were shown to be the source of almost all adipose tissue TNF- $\alpha$ expression and significant amounts of iNOS and IL-6 expression [78]. It is thought that this process is initiated by adipocytes producing low levels of TNF- $\alpha$ in response to FFA. This in turn stimulates pre-adipocytes, endothelial monocyte chemotactic protein-1, adipocytokine expression (IL-6, TNF- $\alpha$, TGF- $\beta 1$ ), iNOS, C-reactive protein, soluble ICAM and NEFA release. All of which further promote pro-inflammatory and pro-oxidative state $[78,79]$. Pro-inflammatory signals induce insulin resistance by inhibiting insulin signalling. TNF- $\alpha$ directly decreases insulin sensitivity in adipocytes by promoting serine phosphorylation of IRS-1 and by impairing tyrosine phosphorylation of insulin receptor. TNF- $\alpha$ also stimulates lipolysis in differentiated human adipocytes through the activation of mitogen-activated protein kinase and extracellular signal-related kinase, and by elevating intracellular cAMP [80]. The activation of other pro-inflammatory pathways such as JNK1, IKK $\alpha$, IKK $\beta$, and PKC are also critical regulators of insulin action [77]. This ultimately leads to hyperglycaemia, glucose intolerance and increased risk of developing the metabolic syndrome and possible onset of T2DM [79]. Furthermore adipose tissue, being an active endocrine organ, secretes a wide range of adipogenic and angiogenic factors such as VEGF, bFGF, IL-6, adiponectin, angiogenin, leptin, IGF-1 and various others. These factors not only play a role in inflammation and oxidative stress resulting in insulin resistance but are also critical factors involved in growth of new vasculature [81]. This enhanced adipose vascular system supplies increased levels of FFA, cytokines and monocytes available to adipose tissue, ultimately perpetuating the progression of obesity, insulin resistance and hyperglycaemia.

\section{Pre-Disposition of Offspring to Later Onset Disease}

There are many long-term pathogenic adaptations that the obese intrauterine environment imparts on offspring. The Barker hypothesis initially focussed on the impact of perinatal under nutrition on later life cardiovascular disease [3] and it has been shown in sheep studies that under nutrition at the time of conception can affect offspring glucose-insulin homeostasis [82]. However recently there has been considerable interest on the foetal programming effects of maternal 'over-nutrition' or obesity. The most important of these are the increased risk of developing lifelong disorders similar to that present in the mother, namely diabetes and obesity, alongside the multitude of associated disorders. These lifelong maladaptation's fuel the perpetual cycle of 'diabesity' which is of great concern. 


\section{Hypothalamic Reprogramming and Epigenetic Modification}

Well documented animal studies have shown that maternal obesity and high-fat diet can cause important alterations in the foetal neuroendocrine system which controls appetite, metabolism and energy expenditure. These processes are tightly regulated by a complex neuronal network of the arcuate nucleus of the hypothalamus (ARH) and the paraventricular nucleus of the hypothalamus (PVH). The most important components are the neurons in the ARH which produce proopiomelanocortin (POMC) and neuropeptide-Y (NPY) and co-expressed agouti-related peptide (AgRP) [76]. These neurons provide overlapping projections to the PVH (among other areas) and have opposing effects on appetite, metabolism and energy expenditure. POMC neurons are potent anorectic regulators that suppress appetite by producing $\alpha$-melanocyte-stimulating hormone ( $\alpha$-MSH). In contrast, the NPY/AgRP neurons act as major orexigenic regulators that stimulate appetite and feeding [83]. Foetal exposure to maternal obesity results in increased expression of orexigenic NPY/AgRP neurons and decreased expression of anorexigenic $\alpha$-MSH. This leads to a lifelong imbalance in the hypothalamic feeding circuitry and persistent hyperphagia. Studies have shown that the adipokine leptin plays a central role in this programming [84].

Leptin is primarily produced by adipose tissue but is also produced by human placenta, the mammary gland (especially in the early stages of lactation), and in gastric peptic cells. Leptin is involved in many diverse biological functions, but for our purposes we will focus on its effect on the hypothalamus where it plays a crucial role in appetite and food intake. Leptin inhibits the activity of orexigenic NPY/AgRP neurons and stimulates the activity of the anorexigenic POMC neurons to supress hunger [84]. However studies have shown that offspring of obese mothers develop a central leptin resistance in the hypothalamus [85], possibly due to an early leptin surge. Recently we have found that lambs born to ewes given late pregnancy propylene glycol had significantly heavier birth weights, ponderal index and plasma glucose levels, and they reached the same carcass weight at an earlier age compared to lambs born to control ewes [86]. This study demonstrated that even transient high glycaemic intakes in the third trimester of pregnancy increased the birth weight of offspring and resulted in faster growth rate in early postnatal life. Kirk et al. [85] found that offspring from obese rats display an amplified and prolonged neonatal leptin surge, and this can lead to central leptin resistance and permanently affect hypothalamic functions involving the ARH and PVH. This may be sufficient to program hyperphagia and obesity in offspring.

Another alternative mechanism of epigenetic programming involves the permanent alteration of DNA expression via changes in methylation status, histone acetylation and phosphorylation [2]. Plagemann et al. [87] reported that pre- and neonatal rat pups exposed to overnutrition developed a permanent disposition to obesity, insulin resistance, and cardiac disorders in adulthood. The authors discovered that this was due to altered DNA methylation patterns in hypothalamic promoter regions of genes critically involved in the lifelong regulation of food intake and body weight. The Plagemann group discovered that the promoter of the main orexigenic neurohormone - NPY - was methylated at low levels, but the hypothalamic gene promoter of the anorexigenic neurohormone - POMC - was hypermethylated at CpG dinucleotides within the two Sp1-related binding sequences (Sp1, NFkB) which are essential for the mediation of leptin and insulin effects on POMC expression [87]. Furthermore, Dunn and Bale [88] showed that alterations in methylation status induced by maternal high-fat diet can be passed to at least two subsequent generations in mice. The authors showed that the methylation status of the growth hormone secretagogue receptor was decreased in the $\mathrm{ARH}$ and was present in the following two generations of offspring from obese and insulinresistant mice. This was associated with an increased expression of secretagogue growth hormone and led to an increase in body length and insulin resistance in offspring $[88,89]$. 
Dowling et al.: The Molecular Mechanisms of Offspring Effects from Obese Pregnancy

\section{Concluding Remarks}

Obesity in pregnancy represents a real and tangible risk both to mothers and their children. Although adult diet and lifestyle are of paramount importance to the development of adult obesity, emerging evidence supports the theory that the origin of adult obesity and related disorders may occur during foetal development and early postnatal life. In this review we have summarised mechanisms by which this can occur, namely maternal body type (apple vs. pear), lipotoxicity, hyperglycaemia, hyperinsulinaemia, insulin resistance, generation of ROS and release of NEFAs, damage to mitochondria and the interference of NO and prostaglandin function. These and many other processes create an unfavourable and arduous environment for the foetus to develop. Placental, cardiovascular, musculoskeletal, neurological and metabolic systems can all suffer as a result. Permanent disorganisation of key hypothalamic regulatory elements and hormonal responses burden the offspring of obese mothers with a predisposition to a plethora of childhood and adult diseases which may potentiate the pathogenic cycle once more. Epigenetic studies of maternal obesity and offspring effects have largely been undertaken in animal models, as investigating humans presents ethical and practical difficulties. In time, more detailed longitudinal human studies should provide a comprehensive analysis of the impact of the obesigenic environment on foetal development. The data available to us at the present time shows that reducing the exposure of foetuses to the obesigenic in utero environment can significantly decrease the risk of obesity and associated metabolic disorders in children and adult offspring [9]. Consequently, obese woman planning a pregnancy should be encouraged to lose weight before conception and during pregnancy should be advised on a suitable diet and weight gain. Continued research into the various intertwined molecular systems will further enable us to focus on effective therapeutic and behavioural interventions. Effectively tackling these issues will help alleviate suffering of future generations and help prevent the intergenerational cycle of obesity and related disorders.

\section{Disclosure Statement}

The authors declare no conflict of interest.

\section{References}

1 Higgins M, Mc Auliffe FM: A review of maternal and fetal growth factors in diabetic pregnancy. Curr Diabetes Rev 2010;6:116-125.

2 Junien C, Nathanielsz P: Report on the IASO Stock Conference 2006: early and lifelong environmental epigenomic programming of metabolic syndrome, obesity and type II diabetes. Obes Rev 2007;8:487-502.

3 Barker DJP: The origins of the developmental origins theory. J Intern Med 2007;261:412-417.

4 Higgins MF, Russell NM, Mulcahy CH, Coffey M, Foley ME, McAuliffe FM: Fetal anterior abdominal wall thickness in diabetic pregnancy. Eur J Obstet Gynecol Reprod Biol 2008;140:43-47.

-5 Herring S, Oken E: Obesity and diabetes in mothers and their children: can we stop the intergenerational cycle? Curr Diabetes Rep 2011;11:20-27.

6 Khandaker GM, Dibben CRM, Jones PB: Does maternal body mass index during pregnancy influence risk of schizophrenia in the adult offspring? Obesi Rev 201213:518-527.

7 Patel SP, Rodriguez A, Little MP, Elliott P, Pekkanen J, Hartikainen A-L, Pouta A, Laitinen J, Harju T, Canoy D, Järvelin MR: Associations between pre-pregnancy obesity and asthma symptoms in adolescents. J Epidemiol Community Health 2012;66:809-814.

8 Barker DJP. Obesity and early life. Obes Rev 2007;8:45-49.

$\rightarrow 9$ Smith J, Cianflone K, Biron S, Hould FS, Lebel S, Marceau S, Lescelleur O, Biertho L, Simard S, Kral JG, Marceau P: Effects of maternal surgical weight loss in mothers on intergenerational transmission of obesity. J Clin Endocrin Metab 2009;94:4275-4283. 


\begin{tabular}{l|l}
\hline Obes Facts 2013;6:134-145 \\
\hline DOI: 10.1159/000350706 & $\begin{array}{l}\text { @ 2013 S. Karger GmbH, Freiburg } \\
\text { www.karger.com/ofa }\end{array}$ \\
\hline
\end{tabular}

Dowling et al.: The Molecular Mechanisms of Offspring Effects from Obese Pregnancy

10 Armitage JA, Lakasing L, Taylor PD, Balachandran AA, Jensen RI, Dekou V, Ashton N, Nyengaard JR, Poston L: Developmental programming of aortic and renal structure in offspring of rats fed fat-rich diets in pregnancy. J Physiol 2005;565:171-184.

11 Fernandes C, Grayton H, Poston L, Samuelsson AM, Taylor PD, Collier DA, Rodriguez A: Prenatal exposure to maternal obesity leads to hyperactivity in offspring. Mol Psychiatry 2012;17:1159-1160.

-12 Oben JA, Patel T, Mouralidarane A, Samuelsson AM, Matthews P, Pombo J, Morgan M, McKee C, Soeda J, Novelli M, Poston L, Taylor P: Maternal obesity programmes offspring development of non-alcoholic fatty pancreas disease. Biochem Biophys Res Commun2010;394:24-28.

13 Samuelsson A-M, Matthews PA, Argenton M, Christie MR, McConnell JM, Jansen EHJM, Piersma AH, Ozanne SE, Twinn DF, Remacle C, Rowlerson A, Poston L, Taylor PD: Diet-induced obesity in female mice leads to offspring hyperphagia, adiposity, hypertension, and insulin resistance. Hypertension 2008;51:383-392.

14 Samuelsson A-M, Morris A, Igosheva N, Kirk SL, Pombo JMC, Coen CW, Poston L, Taylor PD: Evidence for sympathetic origins of hypertension in juvenile offspring of obese rats. Hypertension 2010;55:76-82.

$\checkmark 15$ Henry SL, Barzel B, Wood-Bradley RJ, Burke SL, Head GA, Armitage JA: The developmental origins of obesityrelated hypertension. Clin Exp Pharmacol Physiol 2012;39:799-806.

16 Simmons D: Diabetes and obesity in pregnancy. Best Pract Res Clin Obstet Gynaecol 2011;25:25-36.

17 Ovesen P, Rasmussen S, Kesmodel U: Effect of prepregnancy maternal overweight and obesity on pregnancy outcome. Obstet Gynecol 2011;118:305-312.

18 Lucas A: Programming by early nutrition in man. Ciba Foundation Symposium 1991;156:38-50.

19 Flegal KM, Carroll MD, Ogden CL, Curtin LR: Prevalence and trends in obesity among us adults, 1999-2008. JAMA 2010;303:235-241.

20 Kelly T, Yang W, Chen CS, Reynolds K, He J: Global burden of obesity in 2005 and projections to 2030. Int J Obes 2008;32:1431-1437.

-21 Hyppönen E, Virtanen SM, Kenward MG, Knip M, Akerblom HK, Childhood Diabetes in Finland Study Group: Obesity, increased linear growth, and risk of type 1 diabetes in children. Diabetes Care 2000;23:1755-1760.

22 Jawerbaum A, White V: Animal models in diabetes and pregnancy. Endocr Rev 2010;31:680-701.

23 McGowan CA, McAuliffe FM: The influence of maternal glycaemia and dietary glycaemic index on pregnancy outcome in healthy mothers. Br J Nutr 2010;104:153-159.

-24 Ringrose L, Paro R: Epigenetic regulation of cellular memory by the polycomb and trithorax group proteins. Annu Rev Genet 2004;38:413-443.

-25 HAPO Study Cooperative Research Group, Metzger BE, Lowe LP, Dyer AR, Trimble ER, Chaovarindr U, Coustan DR, Hadden DR, McCance DR, Hod M, McIntyre HD, Oats JJ, Persson B, Rogers MS, Sacks DA: Hyperglycemia and adverse pregnancy outcomes. N Engl J Med 2008;358:1991-2002.

26 Walsh JM, Mahony R, Byrne J, Foley M, McAuliffe FM: The association of maternal and fetal glucose homeostasis with fetal adiposity and birthweight. Eur J Obstet Gynecol Reprod Biol 2011;159:338-341.

-27 Corrigan N, Brazil DP, McAuliffe F: Fetal cardiac effects of maternal hyperglycemia during pregnancy. Birth Defects Res A Clin Mol Teratol 2009;85:523-530.

-28 Jawerbaum A, Gonzalez E: The Role of alterations in arachidonic acid metabolism and nitric oxide homeostasis in rat models of diabetes during early pregnancy. Curr Pharm Des 2005;11:1327-1342.

29 Williams IL, Wheatcroft SB, Shah AM, Kearney MT: Obesity, atherosclerosis and the vascular endothelium: mechanisms of reduced nitric oxide bioavailability in obese humans. Int J Obes Relat Metab Disord 2002; 26(6):754-764.

-30 González E, Jawerbaum A, Novaro V, Sinner D, Gimeno M: Nitric oxide modulates placental prostanoid production from late pregnant non-insulin-dependent diabetic rat. Prostaglandins Leukot Essent Fatty Acids 1998;59:299-304.

-31 Stefan J, Schmieder RE: Impaired endothelial function in arterial hypertension and hypercholesterolemia: potential mechanisms and differences. J Hypertens 2000;18:363-374.

-32 Yoshizumi M, Perrella MA, Burnett JC Jr, Lee ME: Tumor necrosis factor downregulates an endothelial nitric oxide synthase mRNA by shortening its half-life. Circ Res 1993;73:205-209.

-33 Kuboki K, Jiang ZY, Takahara N, Ha SW, Igarashi M, Yamauchi T, Feener EP, Herbert TP, Rhodes CJ, King GL: Regulation of endothelial constitutive nitric oxide synthase gene expression in endothelial cells and in vivo : a specific vascular action of insulin. Circulation 2000;101:676-681.

-34 Thaler CD, Epel D: Nitric oxide in oocyte maturation, ovulation, fertilization, cleavage and implantation: a little dab'll do ya. Curr Pharm Des 2003;9:399-409.

-35 Colton SA, Humpherson PG, Leese HJ, Downs SM: Physiological changes in oocyte-cumulus cell complexes from diabetic mice that potentially influence meiotic regulation. Biol Reprod 2003;69:761-770.

-36 Diamond MP, Moley KH, Pellicer A, Vaughn WK, DeCherney AH: Effects of streptozotocin- and alloxan-induced diabetes mellitus on mouse follicular and early embryo development. J Reprod Fertil 1989;86:1-10.

37 Moley K, Chi M-Y, Knudson C, Korsmeyer S, Mueckler M: Hyperglycemia induces apoptosis in pre-implantation embryos through cell death effector pathways. Nat Med 1998;4:1421-1424.

-38 Moley KH, Chi MM, Mueckler MM: Maternal hyperglycemia alters glucose transport and utilization in mouse preimplantation embryos. Am JPhysiol 11998;275:E38-E47.

39 Moley KH: Diabetes and preimplantation events of embryogenesis. Semin Reprod Med 1999;17:137-151.

40 Wang Q, Moley KH: Maternal diabetes and oocyte quality. Mitochondrion 2010;10:403-410. 
-41 De Hertogh R, Vanderheyden I, Pampfer S, Robin D, Delcourt J: Maternal insulin treatment improves preimplantation embryo development in diabetic rats. Diabetologia 1992;35:406-408.

42 Beckman JS, Koppenol WH: Nitric oxide, superoxide, and peroxynitrite: the good, the bad, and ugly. Am J Physiol 1996;271:C1424-C1437.

43 Cuzzocrea S, Caputi A, Zingarelli B: Peroxynitrite-mediated DNA strand breakage activates poly (ADP-ribose) synthetase and causes cellular energy depletion in carrageenan-induced pleurisy. Immunology 1998;93: 96-101.

44 Tsutsui H, Kinugawa S, Matsushima S: Oxidative stress and heart failure. Am J Physiol Heart Circ Physiol 2011; 301:H2181-H2190.

45 Nakamura T, Goda K, Okamoto T, Kishi T, Nakamura T, Goshima K: Contractile and morphological impairment of cultured fetal mouse myocytes induced by oxygen radicals and oxidants. Correlation with intracellular Ca2+ concentration. Circ Res 1993;73:758-770.

46 Zima AV, Blatter LA: Redox regulation of cardiac calcium channels and transporters. Cardiovasc Res 2006; 71: 310-321.

-47 Cesselli D, Jakoniuk I, Barlucchi L, Beltrami AP, Hintze TH, Nadal-Ginard B, Kajstura J, Leri A, Anversa P: Oxidative stress-mediated cardiac cell death is a major determinant of ventricular dysfunction and failure in dog dilated cardiomyopathy. Circ Res 2001;89:279-286.

-48 Eriksson UJ, Borg LA: Diabetes and embryonic malformations. Role of substrate-induced free-oxygen radical production for dysmorphogenesis in cultured rat embryos. Diabetes 1993;42:411-419.

49 Takimoto E, Kass DA: Role of oxidative stress in cardiac hypertrophy and remodeling. Hypertension 2007;49: 241-248.

50 Cheng T-H, Cheng P-Y, Shih N-L, Chen I-B, Wang DL, Chen J-J: Involvement of reactive oxygen species in angiotensin II-induced endothelin-1 gene expression in rat cardiac fibroblasts. J Am Coll Cardiol 2003;42:18451854.

51 Ieda M, Tsuchihashi T, Ivey KN, Ross RS, Hong T-T, Shaw RM, Srivastava D: Cardiac fibroblasts regulate myocardial proliferation through $\beta 1$ integrin signaling. Dev Cell 2009;16:233-244.

52 Baudino TA, Carver W, Giles W, Borg TK: Cardiac fibroblasts: friend or foe? Am J Physiol Heart Circ Physiol 2006;291:H1015-H1026.

53 Kim S, Iwao H: Molecular and cellular mechanisms of angiotensin ii-mediated cardiovascular and renal diseases. Pharmacol Rev 2000;52:11-34.

54 Sano M, Fukuda K, Sato T, Kawaguchi H, Suematsu M, Matsuda S, Koyasu S, Matsui H, Yamauchi-Takihara K, Harada M, Saito Y, Ogawa S: ERK and p38 MAPK, but not NF- $\kappa B$, are critically involved in reactive oxygen species-mediated induction of IL- 6 by angiotensin II in cardiac fibroblasts. Circ Res 2001;89:661-669.

55 Mills JL, Troendle J, Conley MR, Carter T, Druschel CM: Maternal obesity and congenital heart defects: a population-based study. Am J Clin Nutr 2010;91:1543-1549.

56 Wang J, Ma H, Tong C, Zhang H, Lawlis GB, Li Y, Zang M, Ren J, Nijland MJ, Ford SP, Nathanielsz PW, Li J: Overnutrition and maternal obesity in sheep pregnancy alter the JNK-IRS-1 signaling cascades and cardiac function in the fetal heart. FASEB J 2010;24:2066-2076.

57 Calvert JW, Lefer DJ, Gundewar S, Poston L, Coetzee WA: Developmental programming resulting from maternal obesity in mice: effects on myocardial ischaemia-reperfusion injury. Exp Physiol 2009;94:805-814.

58 Ehrenberg HM, Huston-Presley L, Catalano PM: The influence of obesity and gestational diabetes mellitus on accretion and the distribution of adipose tissue in pregnancy. Am J Obstet Gynecol 2003;189:944-948.

59 Soltani H, Fraser RB: A longitudinal study of maternal anthropometric changes in normal weight, overweight and obese women during pregnancy and postpartum. Br J Nutr 2000;84:95-101.

$\$ 60$ Jarvie E, Hauguel-de-Mouzon S, Nelson SM, Sattar N, Catalano PM, Freeman DJ: Lipotoxicity in obese pregnancy and its potential role in adverse pregnancy outcome and obesity in the offspring. Clin Sci 2010;119: 123-129.

61 Jensen MD: Role of body fat distribution and the metabolic complications of obesity. J Clin Endocrinol Metab 2008;93(11 suppl 1):s57-s63.

62 Gustafson B, Gogg S, Hedjazifar S, Jenndahl L, Hammarstedt A, Smith U: Inflammation and impaired adipogenesis in hypertrophic obesity in man. Am J Physiol Endocrinol Metab 2009;297:E999-E1003.

63 Trauner M, Arrese M, Wagner M: Fatty liver and lipotoxicity. Biochim Biophys Acta 2010;1801:299-310.

64 Imrie H, Abbas A, Kearney M: Insulin resistance, lipotoxicity and endothelial dysfunction. Biochim Biophys Acta 2010;1801:320-326.

65 Pavan L, Hermouet A, Tsatsaris V, Thérond P, Sawamura T, Evain-Brion D, Fournier T: Lipids from oxidized low-density lipoprotein modulate human trophoblast invasion: involvement of nuclear liver X receptors. Endocrinology 2004;145:4583-4591.

66 Zhu MJ, Ma Y, Long NM, Du M, Ford SP: Maternal obesity markedly increases placental fatty acid transporter expression and fetal blood triglycerides at midgestation in the ewe. Am J Physiol Regul Integr Comp Physiol 2010;299:R1224-R1231.

67 Larqué E, Demmelmair H, Berger B, Hasbargen U, Koletzko B: In vivo investigation of the placental transfer of 13C-labeled fatty acids in humans. J Lipid R 2003;44:49-55.

68 Jensen J, Rustad PI, Kolnes AJ, Lai Y-C: The role of skeletal muscle glycogen breakdown for regulation of insulin sensitivity by exercise. Front Physiol. 2011;2:112. 
Dowling et al.: The Molecular Mechanisms of Offspring Effects from Obese Pregnancy

69 Hagemann LL, Zielinsky P: Prenatal study of hypertrophic cardiomyopathy and its association with insulin levels in fetuses of diabetic mothers (in Portugese). Arq Bras Cardiol 1996;66:193-198.

70 Zielinsky P, da Costa MH, Oliveira LT, Bonow FP, da Silva NI, Hagemann LL: Natural history of myocardial hypertrophy and its association with hyperinsulinism in infants of diabetic mothers (in Portugese). Arq Bras Cardiol 1997;69:389-394.

-71 Krüger M, Babicz K, von Frieling-Salewsky M, Linke WA: Insulin signaling regulates cardiac titin properties in heart development and diabetic cardiomyopathy. J Mol Cell Cardiol 2010;48:910-916.

-72 Krüger M, Kötter S, Grützner A, Lang P, Andresen C, Redfield MM, Butt E, dos Remedios CG, Linke WA: Protein kinase G modulates human myocardial passive stiffness by phosphorylation of the titin springs. Circ Res 2009; 104:87-94.

-73 Krüger M, Linke W: Protein kinase-A phosphorylates titin in human heart muscle and reduces myofibrillar passive tension. J Muscle Res Cell Motil 2006;27:435-44.

74 Grützner A, Garcia-Manyes S, Kötter S, Badilla CL, Fernandez JM, Linke WA: Modulation of titin-based stiffness by disulfide bonding in the cardiac titin N2-B unique sequence. Biophys J 2009;97:825-834.

75 Falcão-Pires I, Hamdani N, Borbély A, Gavina C, Schalkwijk CG, van der Velden J, van Heerebeek L, Stienen GJ, Niessen HW, Leite-Moreira AF, Paulus W: Diabetes mellitus worsens diastolic left ventricular dysfunction in aortic stenosis through altered myocardial structure and cardiomyocyte stiffness / clinical perspective. Circulation 2011;124:1151-1159.

-76 Steculorum SM, Bouret SG: Maternal diabetes compromises the organization of hypothalamic feeding circuits and impairs leptin sensitivity in offspring. Endocrinology 2011;152:4171-4179.

-77 Shi H, Kokoeva MV, Inouye K, Tzameli I, Yin H, Flier JS: TLR4 links innate immunity and fatty acid-induced insulin resistance. J Clin Invest 2006;116:3015-3025.

78 Weisberg SP, McCann D, Desai M, Rosenbaum M, Leibel RL, Ferrante AW: Obesity is associated with macrophage accumulation in adipose tissue. J Clin Invest 2003;112:1796-1-808.

79 Roche HM: Fatty acids and the metabolic syndrome. Proc Nutr Soc 2005;64:23-29.

-80 Zhang HH, Halbleib M, Ahmad F, Manganiello VC, Greenberg AS: Tumor necrosis factor- $\alpha$ stimulates lipolysis in differentiated human adipocytes through activation of extracellular signal-related kinase and elevation of intracellular cAMP. Diabetes 2002;51:2929-2935.

-81 Sarkanen J-R, Kaila V, Mannerström B, Räty S, Kuokkanen H, Miettinen S, Ylikomi T: Human adipose tissue extract induces angiogenesis and adipogenesis in vitro. Tissue Eng Part A 2012;18:17-25.

82 Smith NA, McAuliffe FM, Quinn K, Lonergan P, Evans ACO: The negative effects of a short period of maternal undernutrition at conception on the glucose-insulin system of offspring in sheep. Anim Reprod Sci 2010;121: 94-100.

83 Bouret SG, Simerly RB: Developmental programming of hypothalamic feeding circuits. Clin Gene 2006; 70: 295-301.

84 Djiane J, Attig L: Role of leptin during perinatal metabolic programming and obesity. J Physiol Pharmacol 2008; 59:55-63.

85 Kirk SL, Samuelsson AM, Argenton M, Dhonye H, Kalamatianos T, Poston L, Taylor PD, Coen CW: Maternal obesity induced by diet in rats permanently influences central processes regulating food intake in offspring. PLOS ONE 2009;4:e5870.

-86 Smith NA, McAuliffe FM, Quinn K, Lonergan P, Evans ACO: Transient high glycaemic intake in the last trimester of pregnancy increases offspring birthweight and postnatal growth rate in sheep: a randomised control trial. BJOG 2009;116:975-983.

87 Plagemann A, Harder T, Brunn M, Harder A, Roepke K, Wittrock-Staar M, Ziska T, Schellong K, Rodekamp E, Melchior K, Dudenhausen JW: Hypothalamic proopiomelanocortin promoter methylation becomes altered by early overfeeding: an epigenetic model of obesity and the metabolic syndrome. J Physiol 2009;587:49634976.

88 Dunn GA, Bale TL: Maternal high-fat diet promotes body length increases and insulin insensitivity in secondgeneration mice. Endocrinology 2009;150:4999-5009.

-89 Poston L: Developmental programming and diabetes - the human experience and insight from animal models. Best Pract Res Clin Endocrinol Metab 2010;24:541-552. 